\title{
Title: Loss of total phenol in two shrub leaf litter species: the dual role of alpine forest gap disturbance
}

Wei $\mathrm{He}^{2}$, Wanqin Yang ${ }^{1 *}$

${ }^{1}$ School of Life Science, Taizhou University, Taizhou 318000, Zhejiang Province, China.

${ }^{2}$ College of Horticulture and Forestry Sciences/Hubei Engineering Technology Research Center for Forestry Information, Huazhong Agricultural University, Wuhan 430070, China.

Corresponding author (*): W. Yang (E-mail address: scyangwq@163.com),

Tel.: 86-0576-88660339; fax: 86-0576-88660339.

Postal address: School of Life Science, Taizhou University. No. 1139 Shifu avenue, Jiaojiang District, Taizhou 318000, Zhejiang, China 


\section{Abstract}

Alpine forest gaps can distribute snowfall, solar radiation and rainfall, thus inducing a heterogeneous hydrothermal microenvironment between the inside and outside areas of forest gaps. Additionally, the characteristics of the heterogeneous microenvironment could vary greatly across the gap location properties during winter and the growing season. To determine the response of total phenol loss (TPL) from the litter to alpine forest gap disturbance during decomposition, we conducted a field litterbag experiment within a representative fir (Abies faxoniana Rehd.) forest based on the gap location properties. The TPL and abundances of fungi and bacteria from two typical shrub species (willow, Salix paraplesia Schneid., and bamboo, Fargesia nitida (Mitford) Keng f.) were measured during the following periods over two years: snow formation (SF), snow cover (SC) snow melting (ST), the early growing season (EG) and the later growing season (LG). At the end of the study, we found that the snow cover depth, frequencies of the freeze-thaw cycle and the fungal copy $\mathrm{g}^{-1}$ to bacterial copy $\mathrm{g}^{-1}$ ratio had significant effects on the litter TPL. The abundances of fungi and bacteria decreased from the gap center to the closed canopy during the two SF, SC, ST and LG periods and reversed during the two EG periods. The TPL closely followed the same trend as the microbial abundance during the first year of incubation. In addition, both species had larger TPLs in the gap center during the first winter, first year and entire two years. These findings suggest that alpine forest gap formation accelerates litter TPL and plays a dual role during specific critical periods by distributing abiotic and biotic factors directly and indirectly. In conclusion, reduced snow cover depth and duration during winter warming under current climate change scenarios or as gaps vanish may slow litter TPL in alpine biomes. 
Key words: Alpine forest gap; Freeze-thaw cycle; Fungi to bacteria ratio; Snow cover depth; Total phenol 


\section{Introduction}

Widespread tree mortality resulting from global environmental change, frequent geological disasters and artificial interferences is accelerating forest gap formation [1-2]. Generally, more gaps could favor the growth of understory plants and increase their litter production, implying that the litter decomposition of understory plants will become increasingly important in bioelement cycles and site fertility maintenance in forest ecosystems [3]. Polyphenols are well known as plant secondary metabolites that are widely distributed in leaf litter substrates, and these substances can influence the fate of litter decomposition [4]. Little information, however, has been available regarding how gap formation manipulates the temporal dynamics of total phenol in decomposing leaf litter in alpine forest ecosystems [5].

Theoretically, the polyphenols in litter can be rapidly lost by eluviation after litter fall [6]. In most alpine forest ecosystems, however, following the concentration of freshly senesced leaf litterfall, the coming season is winter, which is accompanied by snow cover accumulation [7]. Previous relevant studies revealed that the release of matter, such as condensed tannins [5], lignin [8] and cellulose [3], can be accelerated during the whole winter. We acknowledge that the snow melt period may promote the loss of polyphenols via leaching. However, before snow melt, how the polyphenols in senesced leaf litter are affected during periods of snow formation and coverage remains unknown. Previous studies indicated that the process of litter decomposition during winter is not stagnant due to the relatively higher biotic activities beneath the snow cover, as the insulation provided by snow maintains a sufficiently warm temperature [7,9-10]. However, whether some realistic relationship exists between the loss of polyphenols and surviving microbes is unknown. More importantly, the snow cover depth 
across gap location properties (from the gap center to the closed canopy) could differ greatly during each critical period of winter (such as the snow formation, snow cover and snow melting periods) as a result of sheltering by the canopy $[3,8]$. These characteristics, with varied frequencies of freeze-thaw cycles (FFTCs), temperature and microbes, could have profound repercussions for the loss process of polyphenols in senesced leaf litter. To date, the available information is scarce and cannot be generalized.

In addition, as decomposition proceeds during the growing season, alpine forest ecosystems could experience relatively higher solar radiation levels. As a result of sheltering, the hydrothermal dynamics would differ between the inside and outside of a forest gap, which would significantly regulate the litter decomposition process [11-12]. Furthermore, the crown canopy can control transpiration and intercept rainfall, which may directly and indirectly influence leaching characteristics and microbial activity in situ [13-14]. As mentioned above, the fate of polyphenol loss in leaf litter can vary in the growing season from the gap center to the closed canopy. In addition, the current consensus also suggests that polyphenols participate in the formation of recalcitrant complexes through protein and cellulose precipitation, fungal toxicity gradation and oxidative condensation, all of which slow the litter decomposition process $[5,15]$. Accordingly, the concentration of polyphenols in litter and its dynamics, which are associated with litter decomposition and regulated by forest gap formation, can, in turn, influence litter decomposition and the associated polyphenol loss [16-17]. After reviewing relevant previous studies, we know that the mechanisms affecting litter decomposition can differ between winter and the growing season in high-latitude and high-altitude biomes $[8-9,18]$. However, due to varying changes in litter quality across gap 
location properties following different levels of physical destruction (effects of FFTCs) and biotic decomposition during winter, the consensus on polyphenol loss during the growing season is complicated and unpredictable, which precludes generalizations.

The alpine forest located in the upper reaches of the Yangtze River and on the eastern Tibetan Plateau plays important roles in conserving headwaters and soils, nursing biodiversity and indicating climate change [3]. Based on our previous investigation, there is a visible gradient of snow cover depth among the forest gap location properties (deep snow cover in the gap center and relatively shallow cover under the closed canopy) during winter. Moreover, the current climate change scenarios predict that the snow cover depth and duration will decline in some locations, thus influencing the ecological processes in winter [19-20]. Unfortunately, increasingly well-documented evidence has revealed that this region is extremely sensitive to global climate change [7,21]. In our previous studies $[3,8,11]$, we found that the effects of alpine forest gaps can accelerate litter decomposition and some matter loss during winter and the later growing season, due to the relatively sufficient hydrothermal microenvironment in the gap center as a result of the forest gap distribution. In contrast, the sufficient hydrothermal microenvironments along the expanded edge and in the closed canopy during the early growing season showed the slowed effects of forest gaps on matter loss. Therefore, we hypothesized that alpine forest gap formation also plays two roles in litter polyphenol loss during these critical decomposing periods.

To test the hypotheses, we conducted a field litterbag experiment and measured the total phenol losses from two typical shrub species (willow, Salix paraplesia Schneid., and dwarf 
bamboo, Fargesia nitida (Mitford) Keng f.) in five gap locations (the gap center south, the gap center north, the canopy edge, the expanded edge and the closed canopy). Throughout the two-year study, we focused on the 1) differences in the characteristics of total phenol loss and the associated bacterial and fungal abundances among the species, the gap location properties and specific incubation periods. Furthermore, we 2) determined how the degree of the investigated microenvironment, which is regulated by forest gaps, influenced the total phenol loss in the litter.

\section{Materials and methods}

\subsection{Description of the study site}

We conducted a field litterbag experiment in the Miyaluo Nature Reserve $\left(102^{\circ} 53^{\prime}-102^{\circ} 57^{\prime}\right.$ E, $31^{\circ} 14^{\prime}-31^{\circ} 19^{\prime} \mathrm{N}, 2458-4619 \mathrm{~m}$ a.s.l.), which is located in Li County, Sichuan, southwestern China; the region is a transitional area between the Tibetan Plateau and the Sichuan Basin. The annual mean temperature ranges from 2 to $4{ }^{\circ} \mathrm{C}$, with maximum and minimum temperatures of 23 and $-18{ }^{\circ} \mathrm{C}$, respectively. The annual precipitation is approximately $850 \mathrm{~mm}$. The seasonal soil freeze-thaw period begins in early November after the first snowfall, and the soil remains frozen for 5 to 6 months. The tree canopy is dominated by Sabina saltuaria and Abies faxoniana. The understory shrubs are dominated by Fargesia nitida, Salix paraplesia, Berberis sargentiana, Rhododendron lapponicum, Rosa sweginzowii, Sorbus rufopilosa and other species. The herb layer is dominated by Cystopteris montana, Cacalia spp., Cyperus spp., Carex spp. and other species. A detailed report on the soils in the reserve can be found in [22]. 


\subsection{Design of experiment}

The technique of retrieving litterbags over time was used to assess the leaf litter total phenol loss and the associated abundances of bacteria and fungi in three selected gaps (with similar canopy densities). Each gap measured $25 \mathrm{~m}$ (the circle diameter of the gaps) and was located within a representative fir (Abies faxoniana Rehd.) forest $\left(102^{\circ} 54.72^{\prime}\right.$ E, $31^{\circ} 15.88^{\prime} \mathrm{N} ; 3582$ $\mathrm{m}$ a.s.l.) in the nature reserve. Five positions, measuring $4 \times 4 \mathrm{~m}$ and at intervals of 3-4 $\mathrm{m}$ (to ensure adequate heterogeneous microenvironmental conditions for sampling), were distributed from the gap center to the closed canopy within each gap (the gap center south, the gap center north, the canopy edge, the expanded edge and the closed canopy; adequate details of the study plots can be found in He et al. $[3,8]$.

Leaf litters of freshly senesced willow (Salix paraplesia) and bamboo (Fargesia nitida) were collected from the sampled forest floor in September 2010. After air-drying for at least two weeks at room temperature, the collected leaf litters were placed in nylon bags $(20 \times 20 \mathrm{~cm}$, with a $0.055 \mathrm{~mm}$ mesh on the bottom and a $1.0 \mathrm{~mm}$ mesh on the surface) according to the class of species. When the initial litterbags were prepared, five samples of each species were oven-dried at $65{ }^{\circ} \mathrm{C}$ for $48 \mathrm{~h}$ to determine the moisture content. The moisture content was used to convert the initial air-dried mass of the litter type to its oven-dried mass. Accordingly, the mass of the air-dried leaf litter was equivalent to $10 \mathrm{~g}$ of oven-dried litter for each litterbag. In total, 1500 litterbags ( 3 gaps $\times 5$ positions $\times 2$ species $\times 10$ sampling dates $\times 5$ replicates) were prepared and placed on the forest floor from the gap center to the closed canopy on October 26, 2010. The oven-dried subsamples were used to determine the initial 
chemical compositions of the two leaf litter types [23] (Table 1).

To assess the total phenol loss process and the associated temporal dynamics of the bacterial and fungal abundances, we sampled the litterbags 10 times over 2 years. The 10 sampling dates covered the critical periods of snow formation, coverage and thawing during winter and the high and low solar radiation levels during the growing period for each year (Table 2). The snow thickness was measured with a ruler on each sampling day due to the harsh weather conditions and the lack of an efficient real-time measurement method (Table 3). Fortunately, we placed temperature recorders (iButton DS1923-F5, Maxim/Dallas Semiconductor, Sunnyvale, USA) in the investigated gap locations and recorded the temperature every $2 \mathrm{~h}$.

\subsection{DNA extraction and q-PCR quantification}

Fresh retrieved litter ( $0.3 \mathrm{~g}$ dry weight) was used for DNA extraction using a DNAout kit (Tiandz, Beijing, China). Then, the extracted DNA was purified via agarose electrophoresis using an E.Z.N.A. Gel Extraction kit (Omega Bio-Tek, Norcross, Georgia, USA). These steps can be found in our previous study by Zhao et al. [24]. Additionally, we used purified leaf litter sample DNA as a template, which was amplified by PCR using the following primer and conditions (Table 4). The quantifications of fungi and bacteria were conducted in a CFX96 ${ }^{\mathrm{TM}}$ Real-Time system (Bio-Rad), and the product specificity was confirmed using a melting curve analysis $\left(65-95^{\circ} \mathrm{C}\right.$ and $0.5^{\circ} \mathrm{C}$ per read with a hold time of $\left.5 \mathrm{~s}\right)$.

\subsection{Measurement of total phenol}

The total phenol content was determined with Folin-Ciocalteu's colorimetry with some modifications. Briefly, oven-dried and finely ground leaf litter samples $(0.05 \mathrm{~g})$ were 
transferred to a $15 \mathrm{ml}$ glass tube and suspended in a $70 \%$ acetone solution (the ratio of acetone to water was $7: 3$ ). The tubes were placed in an ultrasonic water bath pot for $40 \mathrm{~min}$ (the temperature, time and power were set to $30^{\circ} \mathrm{C}, 40 \mathrm{~min}$ and 100 , respectively). Then, the mixed solution was transferred to a $10 \mathrm{ml}$ centrifuge tube and centrifuged for $10 \mathrm{~min}$ (the temperature and rotation speed were set at $4{ }^{\circ} \mathrm{C}$ and $5000 \mathrm{r} / \mathrm{min}$, respectively). After adding $9.5 \mathrm{ml}$ of distilled water and $0.5 \mathrm{ml}$ of Folin-Ciocalteu (the Folin-Ciocalteu was diluted with distilled water at a ratio of 1:1), $0.5 \mathrm{ml}$ of the centrifuged solution was transferred to a $25 \mathrm{ml}$ glass tube, and the mixed solution was shaken well. Following the addition of $2.5 \mathrm{ml}$ of $\mathrm{Na}_{2} \mathrm{CO}_{3}(100 \mathrm{~g} / \mathrm{L})$, the mixture was shaken well again and placed in a dark environment for $40 \mathrm{~min}$. Finally, colorimetry was performed at a wavelength of $725 \mathrm{~nm}$.

\subsection{Calculations and statistical analyses}

To characterize the differences in the abiotic factors among the gap locations in each sampling period (defined as the time from the previous sampling date to the current sampling date), we calculated the average temperature (AT) and FFTC based on the daily mean temperature and number of freeze-thaw cycles during specific periods (Table 3). One freeze-thaw cycle was defined as the time period when the temperature dropped below $0{ }^{\circ} \mathrm{C}$ for at least $3 \mathrm{~h}$ and was followed by an increase above $0{ }^{\circ} \mathrm{C}$ for at least $3 \mathrm{~h}$ and vice versa [25]. Each free-thaw cycle was recorded.

The loss of total phenol $(R)$ during each incubation period was calculated as follows:

$R_{t}(\%)=\left(C_{(t-1)}-C_{t}\right) / C_{t 0} \times 100$ 
where $C_{(t-1)}$ and $C_{t}$ represent the content of total phenol on the previous and current sampling dates, respectively, and $\mathrm{C}_{t 0}$ is the initial content of total phenol.

After the pairwise comparisons tests made upon the MANOVA, the responses of the variables (total phenol concentration and the loss, and the fungal copy $\mathrm{g}^{-1}$ to the bacterial copy $\mathrm{g}^{-1}$ ratio) across the gap positions to decomposition time were evaluated with exponential regression or nonparametric LOESS (locally weighted scatterplot smoothing) regression with $95 \%$ confidence intervals (95\% CIs). Detailed post hoc mean comparisons of significant differences in the litter variables (total phenol loss and log numbers of fungal 18S rDNA gene copies and bacterial 16S rDNA gene copies) among gap locations were performed using Tukey's honestly significant difference (HSD) test after the general ANOVA hypothesis was verified. A structural equation model (SEM) was constructed to determine how the total phenol loss was driven by the investigated abiotic and biotic factors in the current study. The Jöreskog's goodness-of-fit index (GFI), root mean square error of approximation (RMSEA), and Bollen-Stine bootstrap test (high $P$ values indicate that the data fit the model well) were used to test the fit of the data to the model [26]. Models with a GFI value greater than 0.9 , an RMSEA value less than 0.08 and a $P$ value greater than 0.05 were chosen. To satisfy the assumptions of normality and homogeneity of variance, the abundance data were $\log (\mathrm{x}+1)$ transformed, and both the abiotic and biotic factor data were standardized with 0-1 normalization prior to the statistical analyses. All analyses were conducted in the Statistical Product and Service Solutions program (SPSS 21.0 for Windows; SPSS Inc., Chicago, IL, USA) and R (R Development Core Team, 2015, http://www.R-project.org/). 


\section{Results}

\subsection{Concentration of total phenol}

The concentration of total phenol showed an exponential decreasing tendency with incubation time, regardless of the gap locations and species (Fig. 1). Among the gap locations, the total phenol concentration was always lower in the gap center than in the expanded edge and the closed canopy during decomposition. Comparing the two species, the total phenol concentration was larger in the willow litter than in the bamboo litter during the winter of the first year (until 128 days of exposure).

\subsection{Loss of total phenol}

The total phenol loss showed a decreasing trend from the gap center to the closed canopy during the snow formation (SF) 1, snow cover (SC) 1, snow melting (ST) 1, the later growing season (LG) 1 and ST2 periods, while this tendency was reversed during the SF2, SC2, early growing season (EG) 1, EG2 and LG2 periods (Fig. 2), regardless of species. Comparing the ten specific periods, relatively higher total phenol loss was indicated for both species in the periods of the first year, especially in the SF1 period of the first winter. There was also an obvious decreasing tendency in total phenol loss from the gap center to the closed canopy for both species during the $\mathrm{W} 1$ period in the first year and whole the 2 year. In contrast, an increasing trend in total phenol loss was found in the two growing seasons (G1 and G2) from the gap center to the closed canopy for both species.

\subsection{Fungal and bacterial quantifications and their ratio}

The log numbers of fungal 18S rDNA gene copies and bacterial 16S rDNA gene copies for 
both species showed a decreasing tendency from the gap center to the closed canopy during the two SF, SC, ST and LG periods. The reverse tendency was shown for the gap location properties during the periods of the two EG periods, although the results varied greatly among the gap locations and decomposition periods (Fig. 3). The fungal copy $\mathrm{g}^{-1}$ to bacterial copy $\mathrm{g}^{-1}$ ratio followed a similar trend as the total phenol loss among the gap location properties during the ten periods (with the exception of two periods, SF1 and SC1) (Fig. 4). In addition, relatively larger values of the ratio among the species and gap location properties occurred in the three periods (SF1, SC1 and ST1) of the first winter.

\subsection{Effects of the abiotic and bioticfactors on the total phenol loss}

Path analysis revealed that three factors (snow cover depth, FFTC and fungal copy $\mathrm{g}^{-1}$ to bacterial copy $\mathrm{g}^{-1}$ ratio) out of the investigated abiotic and biotic factors significantly affected the total phenol loss (Fig. 5). In addition, the snow cover depth directly regulated the FFTC and the fungal copy $\mathrm{g}^{-1}$ to bacterial copy $\mathrm{g}^{-1}$ ratio (although the relationship between snow cover depth and FFTC was not strong), which in turn influenced the total phenol loss.

\section{Discussion}

Over the one-year and entire two-year decomposition periods, a lower total phenol concentration and higher total phenol loss were exhibited for both litter species in the gap center compared to the expanded edge and closed canopy. The results indicated that alpine forest gap formation could accelerate the total phenol loss of plant leaf litter. In addition, during the first year, especially the first winter, an obvious decreasing trend in the total phenol loss from the gap center to the closed canopy was observed for both litter species, 
while there was a reverse tendency across the gap location properties during the two growing seasons. This finding clearly suggests that the pattern of forest gap disturbance on leaf litter phenol loss significantly differed between the winter and growing season.

\subsection{Dual role of alpine forest gap disturbance on total phenol loss}

Our hypothesis, i.e., that alpine forest gap formation would accelerate the total phenol loss during the winter and the later growing season while slowing the total phenol loss during the early growing season, was well supported by our data during the first incubation year. The underlying mechanisms could explain the observed phenomenon. First, during the experimental incubation time of the first winter, we found that there were obvious FFTCs during three critical specific periods (SF1, SC1 and ST1) in the five gap locations, with the exception of the gap center south in SC1 (Table 3). We defined one freeze-thaw cycle as the time period when the temperature was below/above and above/below $0{ }^{\circ} \mathrm{C}$ for at least $3 \mathrm{~h}$ according to [25]. The findings suggested that the effect of leaching on the total phenol loss in the litter occurred in the locations where the FFCTs and snow cover were frequent during specific periods in winter [27]. More importantly, based on our data, there was absolutely no snow ablation in the location of the gap center south during the snow cover period (SC1), while the total phenol loss was largest compared to those in the other four locations (Fig. 2). As expected, during winter, there was an abundance of microbes (fungi and bacteria, Fig. 3) beneath the gap center and the canopy edge. The snow cover depth and effects of insulation at these locations was relatively greater than those in the other gap locations [3,11]. In addition, the path diagrams showed that there was a strong relationship between the fungal copy $\mathrm{g}^{-1}$ to the bacterial copy $\mathrm{g}^{-1}$ ratio and the total phenol loss (Fig. 5). These results are consistent with 
the findings that fungal degradation can influence polyphenol loss via toxicity $[5,15]$. Integrating the leaching role, the decreased abundances of bacteria and fungi accompanied by the reduced snow cover depth from the gap center to the closed canopy (Fig. 3) caused the decrease in total phenol loss across the gap location properties in winter (Fig. 2).

Second, as decomposition proceeded in the early growing season, the solar radiation level was higher in the gap center than in the other gap locations [8]. Although the leaching effect could be stronger in the gap center than in the other locations with crown canopies, we also found that the total phenol loss in the leaf litters of both species was lower in the gap center and higher in the expanded edge and closed canopy (Fig. 2). The possible mechanism behind this finding is that long-term strong solar radiation relative to occasional precipitation caused evaporation to be greater and the microenvironment to be unstable in the gap center, which was unsuitable for the microbes [3]; thus, the locations in the expanded edge and closed canopy, with relatively stable microenvironments and higher levels of microbial activities (Fig. 3), caused the total phenol loss to be relatively greater during the early growing season. Comparatively, as decomposition proceeded during the later growing season, the intensity of solar radiation in the gap center decreased, and precipitation was adequate in that location, contributing to the microbial actions [28] on the total phenol loss.

However, our hypothesis regarding the role of forest gap disturbance on total phenol loss in litter during the second year was not well supported (only the data from the second snow melting and early growing seasons partly supported our hypothesis, Fig. 2). After reviewing our data in the present study, during the first year, the total phenol loss for both species was 
more than $80 \%$ of the initial levels (Fig. 2). The relatively larger proportion of total phenol loss from the litter is consistent with the consensus that the leaching mechanism can induce the rapid loss of polyphenols during the early period of litter decomposition [6]. After rapid loss, the remaining polyphenols can participate in the formation of recalcitrant complexes and combine with other litter components [29], thus influencing the decomposition process during the later decomposition period. Regardless, the data presented in the current study substantially indicated that the forest gaps in alpine biomes play a dual role in total phenol loss in litter by providing shelter from snowfall, solar radiation and rainfall during critical decomposing periods as decomposition proceeds.

\subsection{Effects of species type and biotic factors on the total phenol loss}

Generally, the higher the content of polyphenols in litter is, the lower the decomposition rate in litter [30-32]. In the current study, we chose two shrub species with significant difference in initial litter chemical compositions, and higher initial total phenol concentrations were found in the willow litter (Table 1). However, the decomposition rate was higher in the willow litter than in the bamboo litter during decomposition (detailed information on the decomposition rates of the two species can be found in He et al. [3,8]). In addition, we found that the total phenol concentration was lower in the willow litter than in the bamboo litter after 128 days of incubation in our experiment (after the first winter). Accordingly, our findings suggest that the role of leaching and/or the FFTC during the first winter could significantly affect the total phenol loss in litter with relatively larger leaves and higher concentrations of polyphenols. 
Furthermore, our data also showed the dual role of forest gap disturbance on the abundances of fungi and bacteria across the gap location properties well (Fig. 3). During the winter, abundant fungi and bacteria in the gap center clearly substantiated the insulation of snow cover and maintained a relatively higher level of microbial activity [33-34], contributing to the total phenol loss. More importantly, especially in the first winter, the insulation provided by snow combined with an abundance of soluble materials in the freshly senesced leaf litter selected cold-tolerant microbes [35-36] and induced a higher ratio of fungal copy $\mathrm{g}^{-1}$ to bacterial copy $\mathrm{g}^{-1}$, which might be the key mechanism for the total phenol loss from litter in the alpine forest during winter (Fig. 5).

\section{Conclusion}

Our results obtained in an alpine forest of the eastern Tibetan Plateau clearly showed that alpine forest gap disturbance significantly redistributed snowfall, solar radiation and rainfall, thus inducing decreased snow cover depth from the gap center to the closed canopy during winter and a heterogeneous hydrothermal microenvironment between the inside and outside areas of the forest gap in the growing season. As a result, the dual role of forest gap disturbance on total phenol loss from litter was indicated in the rapid total phenol loss periods (the first year in the present study). Relatively higher levels of microbial activity and a larger leaching role in the gap center throughout the winter accelerated the total phenol loss from the litter. Moreover, as the solar radiation changed from intense to mild in the early and later growing season, the forest gap promoted and slowed total phenol loss from the litter, respectively. The response of the fungal copy $\mathrm{g}^{-1}$ to bacterial copy $\mathrm{g}^{-1}$ ratio to forest gap disturbance seems to be one of the important mechanisms influencing total phenol loss from 
litter. Furthermore, we found that in addition to the first winter, the total litter phenol loss displayed a decreasing trend from the gap center to the closed canopy throughout the first year and the entire two years. This result suggests that the snow cover depth (an index accompanied by the ablation intensity in the snow melting period) and FFTC during winter can have profound repercussions for the process of litter total phenol loss in alpine biomes. Accordingly, in the current climate change scenarios, decreases in the snow cover depth and duration as winters become warmer in the future would inhibit the total phenol loss process in these biomes, which are sensitive to global climate change.

\section{Acknowledgments}

This work was supported by the National Natural Science Foundation of China (No. 31570445 and 31800518).

Author contributions: W. Q. Yang designed the study and proposed the structure of the paper, W. He performed the research and wrote the paper.

Conflicts of Interest: The authors declare no conflict of interest.

\section{Reference}

1. Hicke, J.A.; Zeppel, M.J. Climate-driven tree mortality: insights from the pi.on pine die-off in the United States. New Phytol. 2013, 200, 301-303.

2. Anderegg, W.R.L.; Hicke, J.A.; Fisher, R.A.; Allen, C.D.; Aukema, J.; Bentz, B.; Hood, S.; Lichstein, J.W.; Macalady, A.K.; McDowell, N.; Pan, Y.; Raffa, K.; Sala, A.; Shaw, 
J.D.; Stephenson, N.L.; Tague, C.; Zeppel, M. Tree mortality from drought, insects, and their interactions in a changing climate. New Phytol. 2015, 208, 674-683.

3. He, W.; Wu, F.Z.; Zhang, D.J.; Yang, W.Q.; Tan, B.; Zhao, Y.Y.; Wu, Q.Q. The effects of forest gaps on cellulose degradation in the foliar litter of two shrub species in an alpine fir forest. Plant Soil 2015, 393, 109-122.

4. Kraus, T.E.C.; Dahlgren, R.A.; Zasoski, R.J. Tannins in nutrient dynamics of forest ecosystems - a review. Plant Soil 2003, 256, 41-66.

5. Li, H.; Wu, F.Z.; Yang, W.Q.; Xu, L.Y.; Ni, X.Y.; He, J.; Tan, B.; Hu, Y.; Justin, M.F. The losses of condensed tannins in six foliar litters vary with gap position and season in an alpine forest. iForest 2016, 9, 910-918.

6. Zhou, H.C.; Tam, N.F.Y.; Lin, Y.M.; Wei, S.D.; Li, Y.Y. Changes of condensed tannins during decomposition of leaves of Kandelia obovata in a subtropical mangrove swamp in China. Soil Biol. Biochem. 2012, 44, 113-121.

7. Tan, B.; Wu, F.Z.; Yang, W.Q.; He, X.H. Snow removal alters soil microbial biomass and enzyme activity in a Tibetan alpine forest. Appl. Soil Ecol. 2014, 76, 34-41.

8. He, W.; Wu, F.Z.; Yang, W.Q.; Tan, B.; Zhao, Y.Y.; Wu, Q.Q.; He, M. Lignin degradation in foliar litter of two shrub species from the gap center to the closed canopy in an alpine fir forest. Ecosystems 2016, 19, 115-128.

9. Wu, Q.Q. Effects of snow depth on acid-unhydrolyzable residue and acid-hydrolyzable carbohydrates degradation rates during foliar litter decomposition of Pinus koraiensis and Quercus mongolica. Plant Soil 2018, 428, 389-400.

10. Wu, F.Z.; Yang, W.Q.; Zhang, J.; Deng, R.J. Litter decomposition in two subalpine forests 
during the freeze-thaw season. Acta Oecol. 2010, 36, 135-140.

11. He, W.; Wu, F.Z.; Yang, W.Q.; Zhang, D.J.; Xu, Z.F.; Tan, B.; Zhao, Y.Y.; Justine, M.F. Gap locations influence the release of carbon, nitrogen and phosphorus in two shrub foliar litter in an alpine fir forest. Sci. Rep-UK. 2016, doi: 10.1038/srep22014.

12. Zhang, Q.S.; Zak, J.C. Potential physiological activities of fungi and bacteria in relation to plant litter decomposition along a gap size gradient in a natural subtropical forest. Microb. Ecol. 1998, 35, 172-179.

13. Zhang, Q.S.; Liang, Y.W. Effects of gap size on nutrient release from plant litter decomposition in a natural forest ecosystem. Can. J. For. Res. 1995, 25, 1627-1638.

14. Zhang, Q.S.; Zak, J.C. Effects of gap size on litter decomposition and microbial activity in a subtropical forest. Ecology 1995, 76, 2196-2204.

15. Hagerman, A.E.; Riedl, K.M.; Jones, G.A.; Sovik, K.N.; Ritchard, N.T.; Hartzfeld, P.W.; Riechel, T.L. High molecular weight plant polyphenolics (tannins) as biological antioxidants. J. Agr. Food Chem. 1998, 46, 1887-1892.

16. Yue, K.; García-Palacios, P.; Parsons, S.A.; Yang, W.Q.; Peng, Y.; Tan, B., Huang, C.P.; Wu, F.Z. Assessing the temporal dynamics of aquatic and terrestrial litter de composition in an alpine forest. Funct. Ecol. 2018, 32, 2464-2475.

17. García-Palacios, P.; McKie, B.G.; Handa, I.T.; Frainer, A.; Hättenschwiler, S. The importance of litter traits and decomposers for litter decomposition: A comparison of aquatic and terrestrial ecosystems within and across biomes. Funct. Ecol. 2016, 30, 819-829. https:// doi.org/10.1111/1365-2435.12589

18. Tan, B.; Zhang, J.; Yang, W.Q.; Yin, R.; Xu, Z.F.; Liu, Y.; Zhang, L.; Li, H.; You, C.M. 
Forest gaps retard carbon and nutrient release from twig litter in alpine forest ecosystems. Eur. J. Forest Res. 2019, Doi: 10.1007/s10342-019-01229-8.

19. Wipf, S.; Stoeckli, V.; Bebi, P. Winter climate change in alpine tundra: plant responses to changes in snow depth and snowmelt timing. Nat. Clim. Change 2009, 94, 105-121.

20. Campbell, J.L.; Socci, A.M.; Templer, P.H. Increased nitrogen leaching following soil freezing is due to decreased root uptake in a northern hardwood forest. Glob. Chang Biol. 2014, 20, 2663-2673.

21. Zhu, J.X.; He, X.H.; Wu, F.Z.; Yang, W.Q.; Tan, B. Decomposition of Abies faxoniana litter varies with freeze-thaw stages and altitudes in subalpine/alpine forests of southwest China. Scand. J. For. Res. 2012, 27, 586-596.

22. Zhu, J.X.; Yang, W.Q.; He, X.H. Temporal dynamics of abiotic and biotic factors on leaf litter of three plant species in relation to decomposition rate along a subalpine elevation gradient. PLoS ONE 2013, 8:e62073.

23. Lu, R. Soil and agro-chemical analytical methods. China Agricultural Science and Technology Press, Beijing, 1999, 146-195. [in Chinese, English abstract]

24. Zhao, Y.Y.; Wu, F.Z.; Yang, W.Q.; Tan, B.; He, W. Variations in bacterial communities during foliar litter decomposition in the winter and growing seasons in an alpine forest of the eastern Tibetan Plateau. Can. J. Microbiol. 2016, 62, 35-48.

25. Konestabo, H.S.; Michelsen, A.; Holmstrup, M. Responses of springtail and mite populations to prolonged periods of soil freeze-thaw cycles in a sub-arctic ecosystem. Appl. Soil Ecol. 2007, 36, 136-146.

26. Guo, G.; Kong, W.; Liu, J.; Zhao, J.; Du, H.; Zhang, X.; Xia, P. Diversity and distribution 
of autotrophic microbial community along environmental gradients in grassland soils on the Tibetan Plateau. Appl. Microbiol. Biot. 2015, 99, 8765-8776.

27. Groffman, P.M.; Driscoll, C.T.; Fahey, T.J.; Hardy, J.P.; Fitzhugh, R.D.; Tierney, G.L. Effects of mild winter freezing on soil nitrogen and carbon dynamics in a northern hardwood forest. Biogeochemistry, 2001, 56, 191-213.

28. Prescott, C.E. Litter decomposition: what controls it and how can we alter it to sequester more carbon in forest soils? Biogeochemistry, 2010, 101, 133-149.

29. Haase, K.; Wantzen, K.M. Analysis and decomposition of condensed tannins in tree leaves. Environ. Chem. Lett. 2008, 6, 71-75.

30. Berg, B.; McClaugherty, C. Plant litter. Decomposition, Humus Formation, Carbon Sequestration, 3rd ed.; Springer: Berlin, Germany. 2014.

31. Driebe, E.M.; Whitham, T.G. Cottonwood hybridization affects tannin and nitrogen content of leaf litter and alters decomposition. Oecologia 2000, 123, 99-107.

32. Kalburtji, K.L.; Mosjidis, J.A.; Mamolos, A.P. Litter dynamics of low and high tannin sericea lespedeza plants under field conditions. Plant Soil 1999, 208, 271-281.

33. Saccone, P.; Morin, S.; Baptist, F.; Bonneville, J.M.; Colace, M.P.; Domine, F. The effects of snowpack properties and plant strategies on litter decomposition during winter in subalpine meadows. Plant soil 2013, 363, 215-229.

34. Campbell, J.L.; Mitchell, M.J.; Groffman, P.M.; Christenson, L.M.; Hardy, J.P. Winter in northeastern North America: a critical period for ecological processes. Front. Ecol. Environ. 2005, 3, 314-322.

35. Wilson, S.L.; Walker, V.K. Selection of Low-Temperature Resistance in Bacteria and 
Potential Applications. Environ. Technol. 2010, 31, 943-956.

36. Walker, V.K.; Palmer, G.R.; Voordouw, G. Freeze-Thaw Tolerance and Clues to the Winter Survival of a Soil Community. Appl. Environ. Microb. 72, 1784-1792.Wipf, S.; Stoeckli, V.; Bebi, P.; 2009. Winter climate change in alpine tundra: plant responses to changes in snow depth and snowmelt timing. Clim. Chang 2006, 94, 105-121.

37. Gardes, M.; Bruns, T.D. ITS primers with enhanced specificity of basidiomycetes: application to the identification of mycorrhizae and rusts. Mol. Ecol. 2008, 2, 113-118.

38. Vilgalys, R.; Hester, M. Rapid genetic identification and mapping of enzymatically amplified ribosomal DNA from several Cryptococcus species. J. Bacteriol. 1990, 172, 4238-4246.

39. Lane, D. 16S/23S rRNA sequencing, In: Stackebrandt, A and Goodfellow, M (eds). Nucleic Acid Techniques Systematics. John Wiley: West Sussex, UK. 1991, 115-175.

40. Muyzer, G.; Waal, E.C.D.; Uitterlinden, A.G. Profiling of complex microbial populations by denaturing gradient gel electrophoresis analysis of polymerase chain reaction-amplified genes coding for 16S rRNA. Appl. Environ. Microb. 1993, 59, 695-700. 
1 Table 1 Initial litter chemistry in the foliar litters of Fargesia nitida and Salix paraplesia $($ mean \pm SD, n=5).

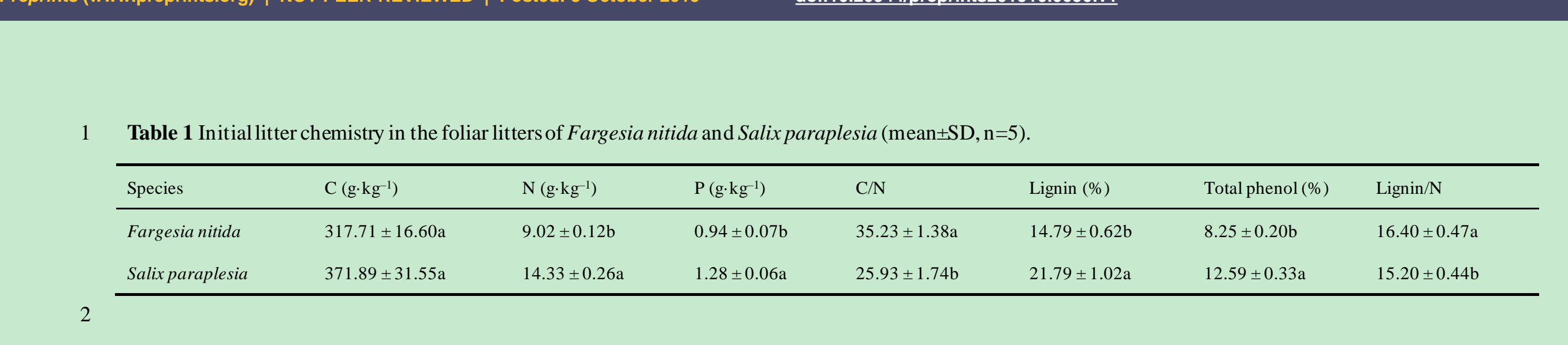

2 \\ doi:10.20944/preprints201910.0090.v1}

(1)

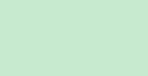

(1)


3 Table 2 Sampling dates, the corresponding days of litterbag exposure and the specific seasonal periods.

\begin{tabular}{lllllllllll}
\hline Sample NO. & 1 & 2 & 3 & 4 & 5 & 6 & 7 & 8 & 9 \\
\hline Sampling date & $2010-12-23$ & $2011-03-03$ & $2011-04-19$ & $2011-08-19$ & $2011-11-08$ & $2011-12-27$ & $2012-03-07$ & $2012-04-28$ & $2012-08-25$ & $2012-10-29$ \\
Days of litterbag exposure & 58 & 128 & 175 & 297 & 378 & 427 & 498 & 550 & 669 & 734 \\
Seasonal period & $\mathrm{SF} 1$ & $\mathrm{SC} 1$ & $\mathrm{ST} 1$ & $\mathrm{EG} 1$ & $\mathrm{LG} 1$ & $\mathrm{SF} 2$ & $\mathrm{SC} 2$ & ST2 & EG2 & LG2 \\
\hline
\end{tabular}

4 SF1, the first snow formation period; SC1, the first snow cover period; ST1, the first snow melting period; EG1, the first early growing period; LG1, the first later

5 growing period; $\mathrm{SF} 2$, the second snow formation period; $\mathrm{SC} 2$, the second snow cover period; $\mathrm{ST} 2$, the second snow melting period; $\mathrm{EG} 2$, the second early growing

6 period; and LG2, the second later growing period. 
8 Table 3 Snow cover depth (SCD, cm), average temperature (AT, ${ }^{\circ} \mathrm{C}$ ) and frequency of the freeze-thaw cycle (FFTC, times) from the gap center to the closed canopy

9 in each specific period of decomposition.

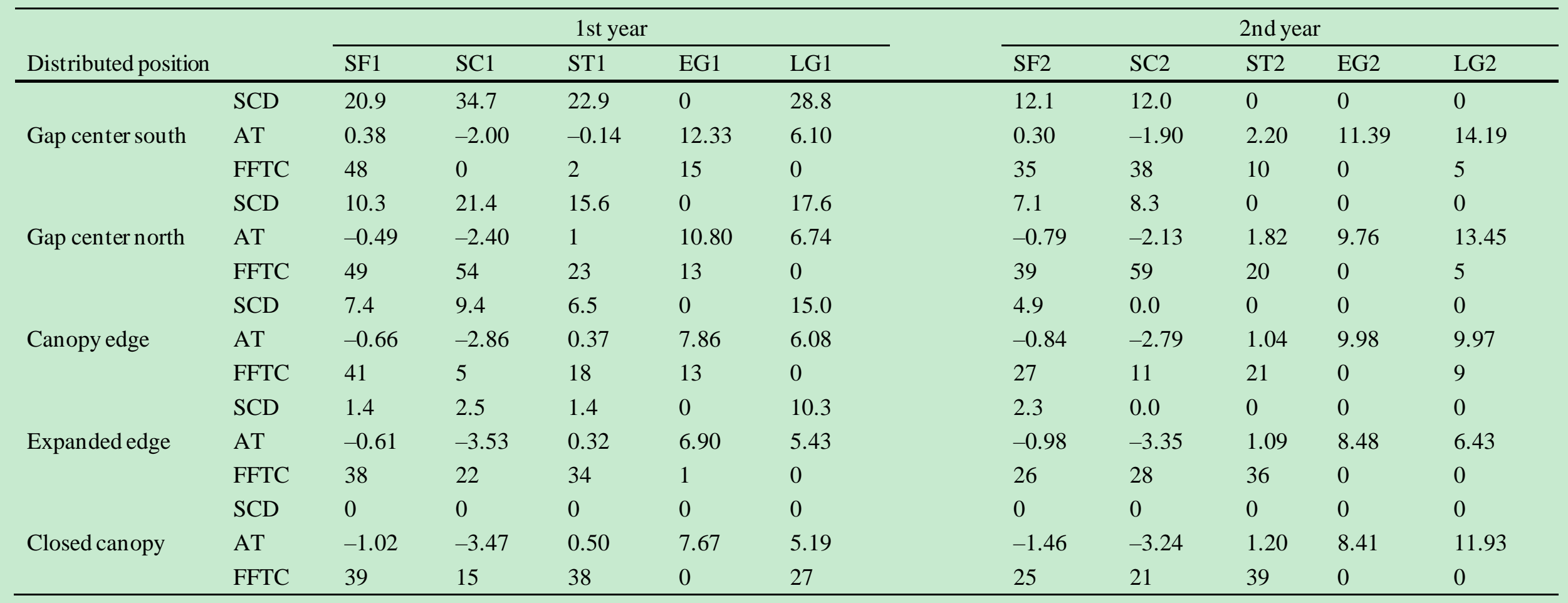

10 
12 Table 4 Primer and PCR conditions used for the real-time quantitative PCR.

\begin{tabular}{|c|c|c|c|c|c|}
\hline \multirow[t]{6}{*}{12} & \multicolumn{5}{|c|}{ Table 4 Primer and PCR conditions used for the real-time quantitative PCR. } \\
\hline & Target group & Primer & Primer sequence $\left(5^{\prime}-3^{\prime}\right)$ & Thermal profile & Reference \\
\hline & \multirow[t]{2}{*}{ Fungi } & $5.8 \mathrm{~s}$ & CGC TGC GTT CTT CAT CG & $30 \mathrm{~s}$ at $98^{\circ} \mathrm{C}$, followed by 40 cycles of $10 \mathrm{~s}$ at $98^{\circ} \mathrm{C}, 30 \mathrm{~s}$ at $53^{\circ} \mathrm{C}$ and $30 \mathrm{~s}$ at & [37] \\
\hline & & ITS1f & TCC GTA GGT GAA CCT GCG G & $72{ }^{\circ} \mathrm{C}$, plate read after each cycle. & {$[38]$} \\
\hline & \multirow[t]{2}{*}{ Bacteria } & Eub338 & ACT CCT ACG GGA GGC AGC AG & 30 s at $98{ }^{\circ} \mathrm{C}$, followed by 35 cycles of $10 \mathrm{~s}$ at $98^{\circ} \mathrm{C}, 30 \mathrm{~s}$ at $54^{\circ} \mathrm{C}$ and $30 \mathrm{~s}$ at & [39] \\
\hline & & Eub518 & ATT ACC GCG GCT GCT GG & $72{ }^{\circ} \mathrm{C}$, plate read after each cycle. & [40] \\
\hline
\end{tabular}

.




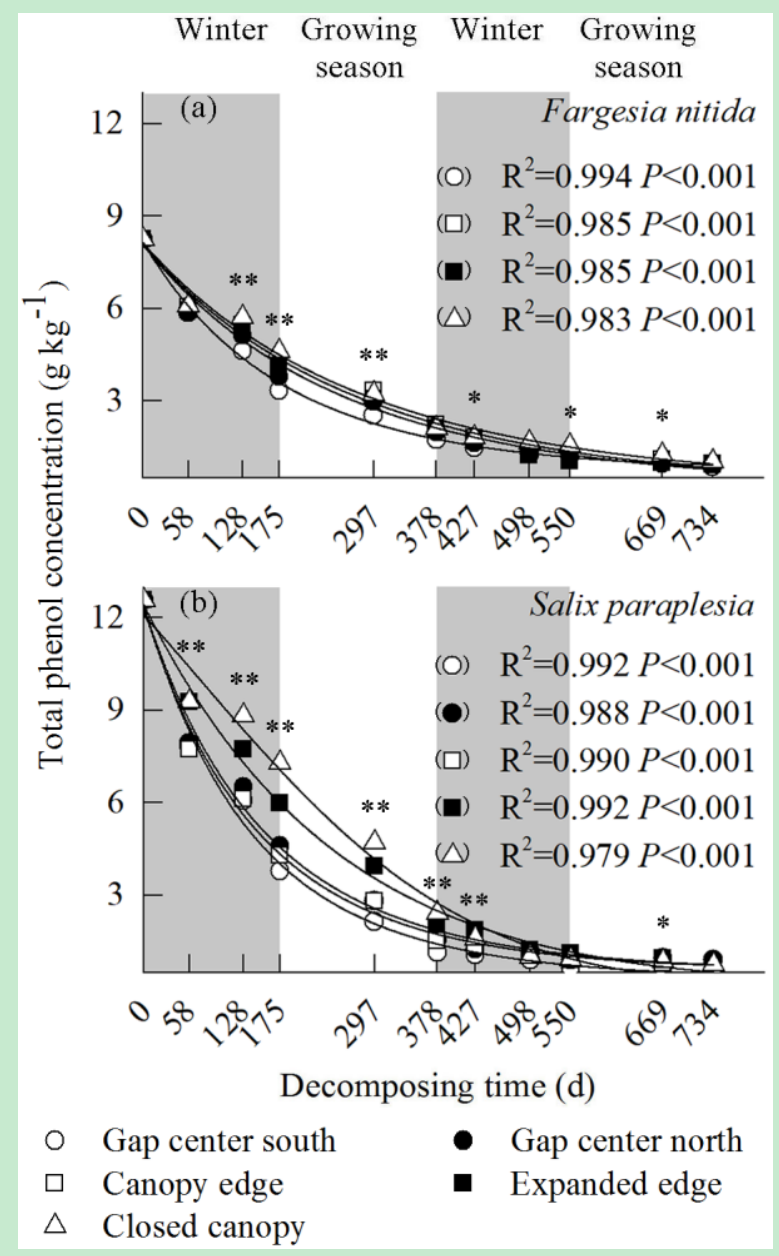

Fig. 1 Exponential regressions of the total phenol concentration $\mathrm{s}$ in the foliar litters of Fargesia nitida and Salix paraplesia from the gap center to the closed canopy to the decomposition time (mean, $n=3$ ). The insets show the statistical significance levels, $* * P<0.01$ and $* P<0.05$, for the effects of gap location on the total phenol concentration. 


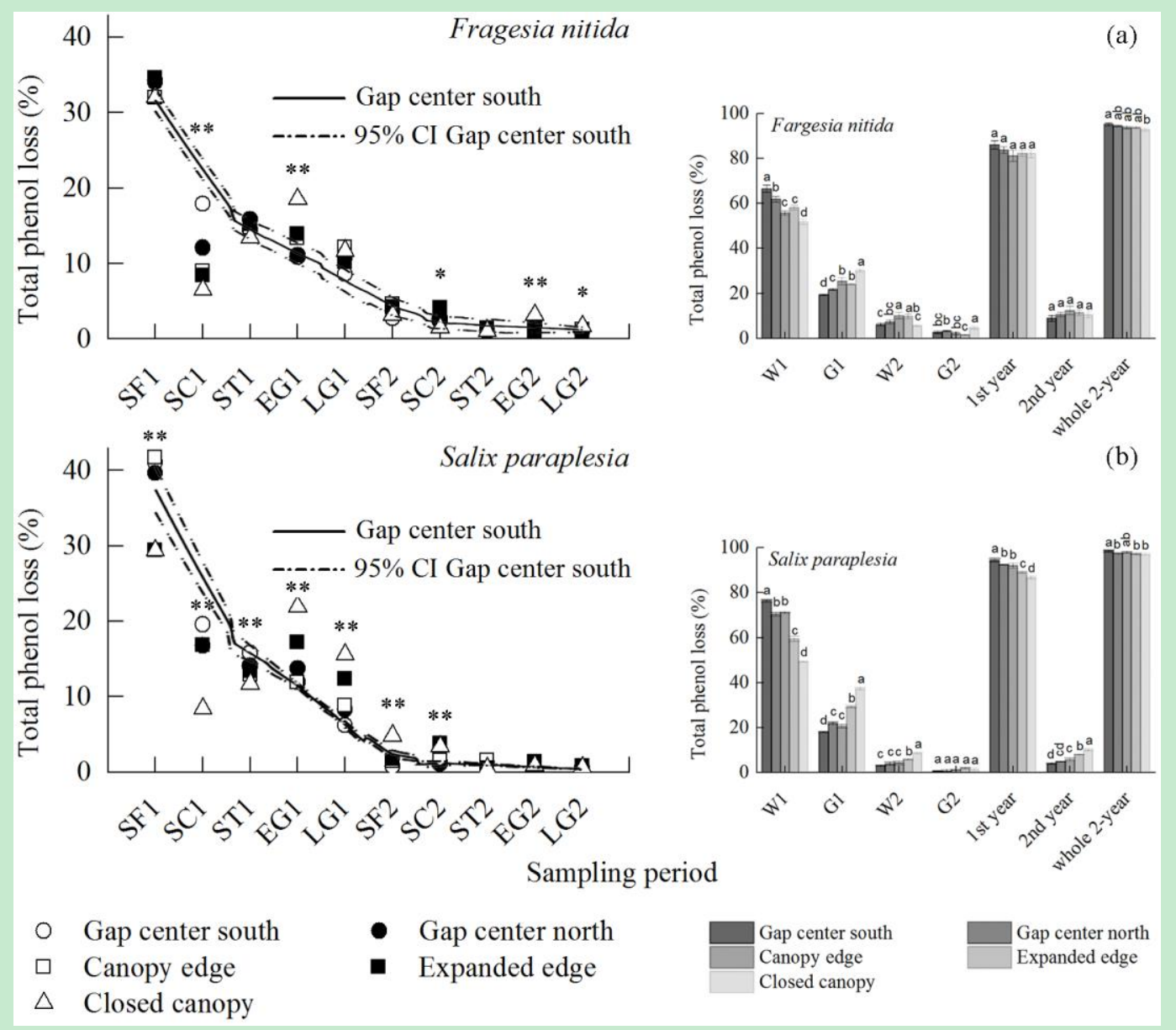

Fig. 2 Total phenol loss (mean $\pm 95 \%$ confidence intervals or mean $\pm \mathrm{SD}, n=3$ ) in the Fargesia nitida and Salix paraplesia foliar litters from the gap center to the closed canopy in specific periods of decomposition. The insets show the statistical significance levels, ** $P<0.01$ and $* P<0.05$, for the effects of gap location on the total phenol loss. Columns marked with different lowercase letters indicate a significant difference among gap positions within the same decomposition period. SF1, the first snow formation period; SC1, the first snow cover period; ST1, the first snow melting period; EG1, the first early growing period; LG1, the first later growing period; SF2, the second snow formation period; $\mathrm{SC} 2$, the second snow cover period; ST2, the second snow melting period; EG2, the second early growing period; LG2, the second later growing period; W1, first winter period; G1, first growing period; W2, second winter period; and G2, second growing period. 


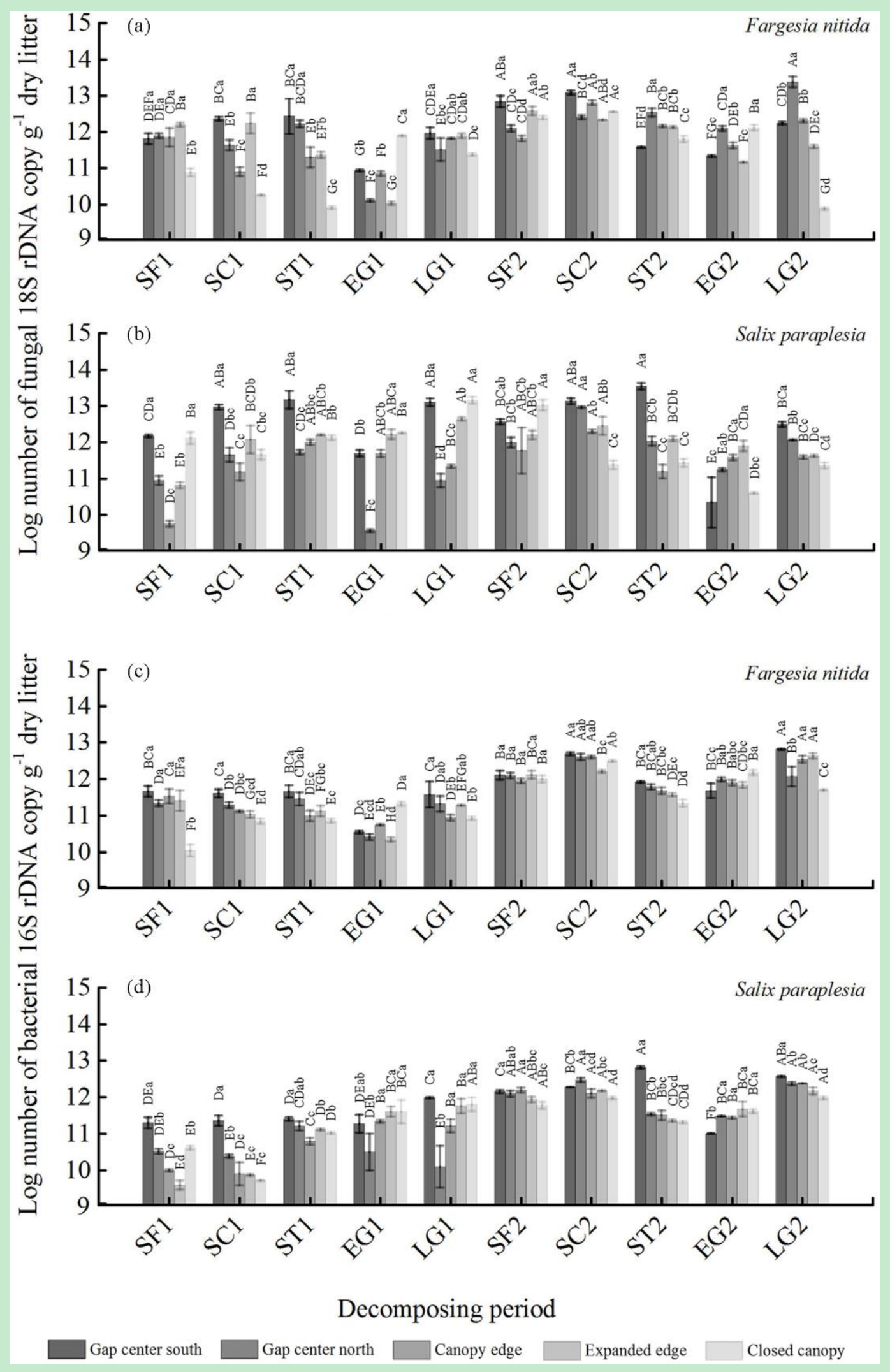

Fig. 3 Log numbers of fungal 18S rDNA gene copies and bacterial 16S rDNA gene copies in the foliar litters of Fargesia nitida and Salix paraplesia from the gap center to the closed canopy in specific periods of decomposition (mean $\pm \mathrm{SD}, \mathrm{n}=3$ ). Different capital letters indicate significant differences $(P<0.05)$ among different decomposition periods for the same gap location. Different lowercase letters indicate 
significant differences $(P<0.05)$ among different gap locations for the same decomposition period. SF1, the first snow formation period; SC1, the first snow cover period; ST1, the first snow melting period; EG1, the first early growing period; LG1, the first later growing period; SF2, the second snow formation period; $\mathrm{SC} 2$, the second snow cover period; ST2, the second snow melting period; EG2, the second early growing period; and LG2, the second later growing period. 


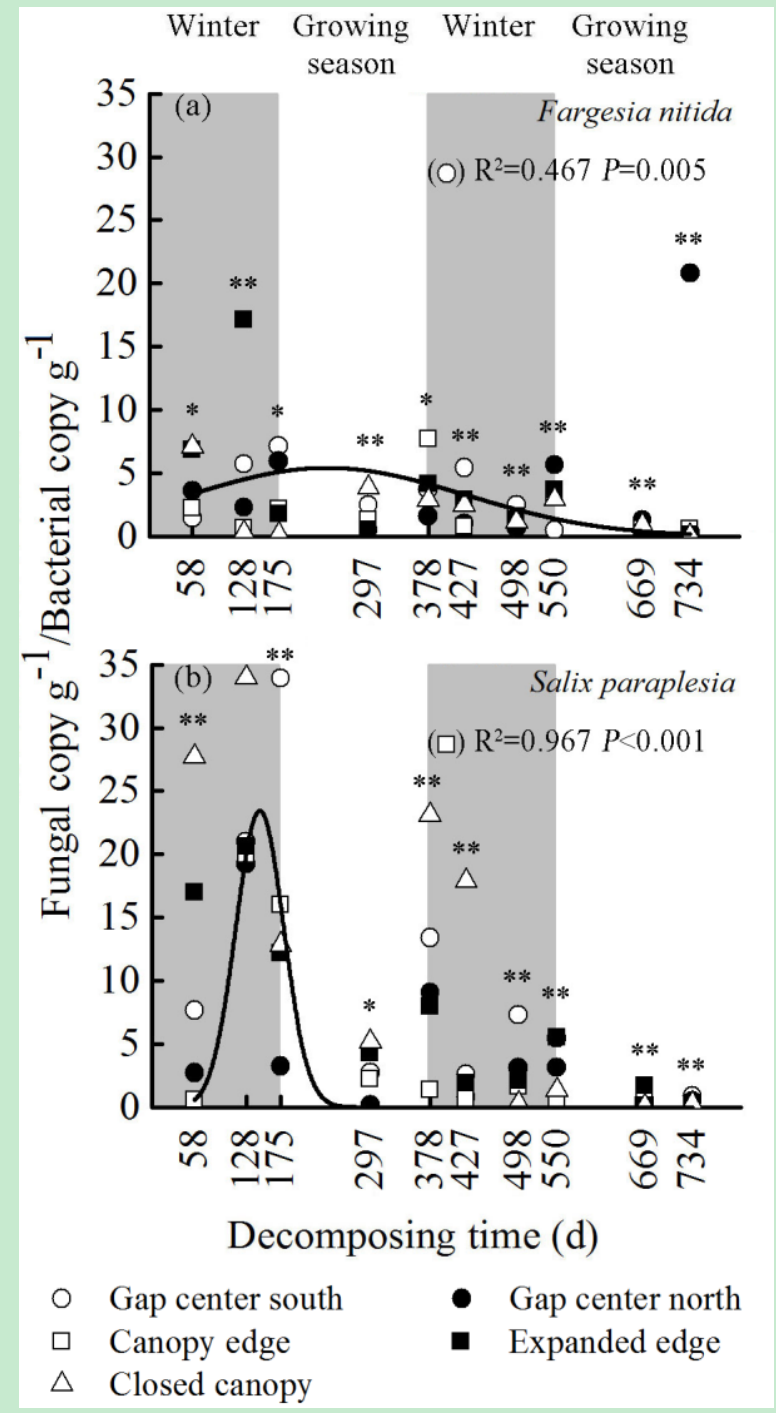

Fig. 4 Exponential regression of the fungal copy $\mathrm{g}^{-1}$ to bacterial copy $\mathrm{g}^{-1}$ ratio in the foliar litters of Fargesia nitida and Salix paraplesia to the decomposition time from the gap center to the closed canopy (mean, $\mathrm{n}=3$ ). The insets show the statistical significance levels, $* * P<0.01$ and $* P<0.05$, for the effects of gap location on the fungal copy $\mathrm{g}^{-1}$ to bacterial copy $\mathrm{g}^{-1}$ ratio. 


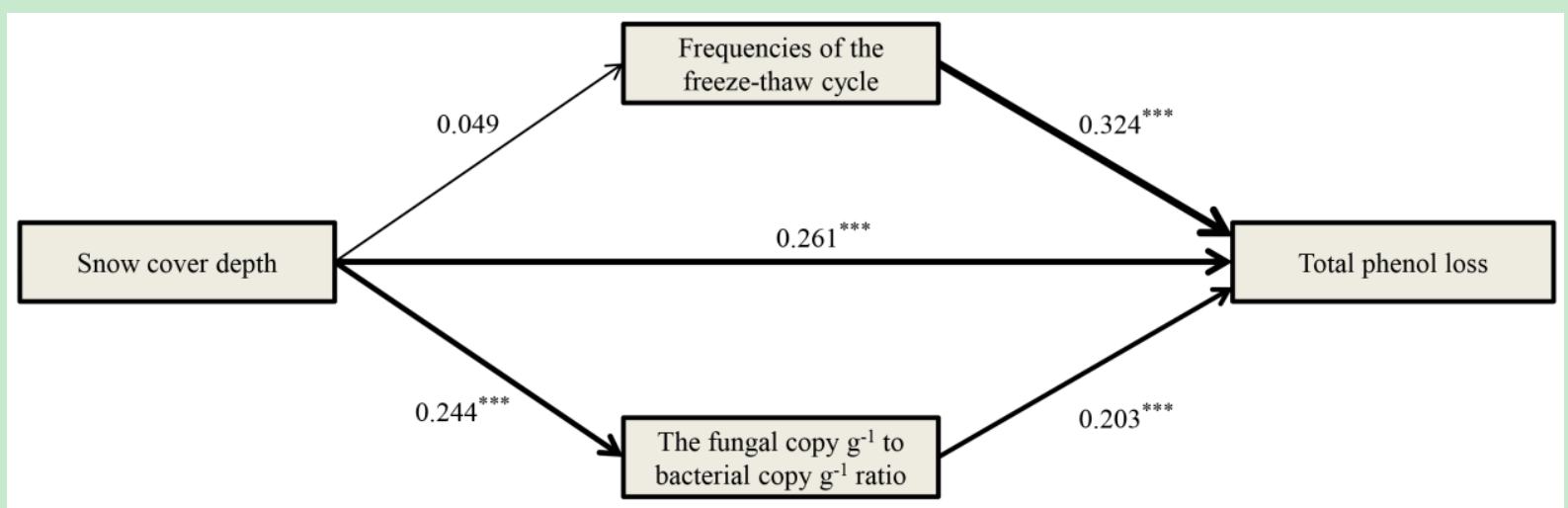

Fig. 5 Path diagram showing the direct and indirect effects of snow cover depth, frequencies of the freeze-thaw cycle and the fungal copy $\mathrm{g}^{-1}$ to bacterial copy $\mathrm{g}^{-1}$ ratio on the total phenol loss. The line width indicate the relative strengths of the paths. Significance: $* * * P<0.001$. 